\title{
Acute lymphoblastic leukaemia among Spanish children and mothers' occupation: a case-control study
}

Claire Infante-Rivard, Patricia Mur, Ben Armstrong, Carlos Alvarez-Dardet, Francisco Bolumar

\begin{abstract}
Study objective-The aim was to investigate the association between mothers' occupational exposure during pregnancy and the incidence of acute lymphoblastic leukaemia in children.

Design-The study was a case-control investigation. A face to face interview was used to assess exposures at work and relevant confounding variables.
\end{abstract}

Setting-The study was community based and was carried out in five provinces of Spain.

Subjects-128 cases less than 15 years of age were interviewed ( $91 \%$ of those eligible). Controls (one for each case) were chosen from the census lists and were matched on year of birth, sex, and municipality.

Measurements and main resultsChildren of mothers working at home had a relative risk $(R R)$ of $7 \cdot 0(95 \% \mathrm{CI}=1 \cdot 59-30 \cdot 79)$ of developing acute lymphoblastic leukaemia. Exposure to organic dust was associated with a $R R$ of $5.5(95 \% \mathrm{CI}=1 \cdot 21-$ 24.8). There was a statistically significant interaction between exposure to organic dust and working at home. The majority of women working at home were hired by local industries to sew different types of tissues (cotton, wool, synthetic fibres) on a machine.

Conclusions-A similar association has not been reported before: if confirmed, this finding may suggest a new health concern.

\section{School of}

Occupational Health, McGill University, 1130 Pine Avenue West, Montreal, Quebec, Canada H3A 1A3

C Infante-Rivard

B Armstrong

Division de Medicina

Preventiva y Social,

Departamento de

Salud Communitaria,

Universitad de

Alicante, San Vicente

Del Raspeig, Alicante,

Spain

C Alvarez-Dardet

F Bolumar

Correspondence to:

Dr Infante-Rivard

Accepted for publication June 1990
Among children between the ages of five and 14 years, cancer is the second cause of death, preceded only by accidents, and in the age group of one to four years, it is the third cause of death after accidents and congenital anomalies. Leukaemia is the most common malignancy among children with a peak incidence between two and four years old. Almost $80 \%$ of the leukaemias in this age group are of the acute lymphoblastic type. Suggested risk factors for childhood acute leukaemias have recently been critically reviewed. ${ }^{1}$ They include genetic factors, birth characteristics, prenatal exposure to exogeneous hormones, irradiation, ultrasound, viral infections, and postnatal irradiation. More recently, exposure to electromagnetic fields ${ }^{2}$ and parental occupation ${ }^{3}$ have also been assessed as potential causes of childhood cancer. In this work, parental occupation will be the focus of interest, and in particular, mother's occupation during pregnancy.
The plausibility of an association between parental occupation and childhood cancer has been evoked before ${ }^{4}$ : one of the suggested mechanisms is through direct damage to the parents' germ cells during preconception, by certain known carcinogens (for example, hydrocarbons). A second possible mechanism is the mother's exposure before and during pregnancy to soiled clothes brought home from the workplace by the father. This in turn could lead to chromosome defects. Finally, the direct exposure of the child to carcinogenic material brought home from the workplace may cause carcinogenesis.

Several studies have been published on the association of parental occupation and childhood leukaemia ${ }^{5-21}$ although some did not examine mother's occupation, 56111314 and others did not pursue the analysis of mother's occupation because the majority of women were classified as homemakers. ${ }^{712}$ Some studies have found no association between mother's occupation and childhood leukaemia, 89182021 while others have. ${ }^{10}{ }^{15-17} 19$ In a study from Finland, ${ }^{10}$ no maternal occupation could be incriminated as a specific risk factor for leukaemia (all types). However, when the mother worked as a pharmacist during pregnancy, the child was more likely to develop a malignancy [odds ratio $(O R)=3 \cdot 2, p<0 \cdot 05$ ]. Parents' occupations were determined from the records at the maternity welfare centres. In a recent study from Los Angeles County, ${ }^{15}$ parents' occupational exposures and personal habits as well as home exposures assessed through interviews were studied in relation to acute leukaemia (lymphocytic and non-lymphocytic). Cases were 10 years of age or less at the time of diagnosis from 1980 to 1984 . Mothers' employment in the personal service industries was associated with an increased risk of leukaemia $(O R=2 \cdot 7, p=0.04)$. However, no significant association was found when mothers' exposures to specific solvents was assessed. The use of household pesticides during pregnancy or during nursing showed an association with the incidence of acute leukaemia $[\mathrm{OR}=3.8,95 \%$ confidence interval $(\mathrm{CI})=1.37-$ 13.02]. Preliminary data from a study by Buckley et $a l^{16}$ suggested that mothers' occupational exposures to pesticides and to metals were associated with an increased risk of acute nonlymphocytic leukaemia.

Van Steensel-Moll et $a l^{17}$ performed the only study limited to cases of acute lymphocytic leukaemia in association with parental occupation. Cases were from the Netherlands, and aged less than 15 years at the time of diagnosis between 1973 and 1980. Mother's occupation was 
assessed during pregnancy and one year before diagnosis, using a mail questionnaire. The relative risk (RR) for mothers working in the textile industry during pregnancy was $4.2(95 \%$ $\mathrm{CI}=1 \cdot 0-17 \cdot 7$ ). Exposure to chemicals (paint, petroleum products, and other unspecified chemicals) during the same period was reported significantly more often by mothers of cases than by mothers of controls $\left(\mathrm{RR}=2 \cdot 4,95^{\circ} \mathrm{CI}=1 \cdot 2-\right.$ $4 \cdot 6)$. None of the exposures during the year before diagnosis seemed to affect the incidence of acute lymphoblastic leukaemia. Adjustment for age, sex, place of residence, birth order, and social class did not change the relative risks. The results of a case-control study of childhood leukaemia in Shanghai were recently reported; ${ }^{19}$ excess risks for acute lymphoblastic leukaemia were associated with maternal employment in the chemical industry during pregnancy $(\mathrm{OR}=3 \cdot 2$, $95 \% \mathrm{CI}=1 \cdot 5-7 \cdot 0)$ as well as with occupational exposure to gasoline $\left(\mathrm{OR}=1 \cdot 7,95^{\circ}{ }_{0} \mathrm{CI}=1 \cdot 0\right.$ $3 \cdot 0)$ and to pesticides $(\mathrm{OR}=3 \cdot 5,95 \% \mathrm{CI}=1 \cdot 1$ 11.2). In a preliminary report, Feingold and Savitz ${ }^{20}$ showed an association between aromatic amino compound exposures of mothers and brain cancer in children.

The objective of the present study was to assess the relationship between mother's occupation during pregnancy and the incidence of acute lymphoblastic leukaemia among children less than 15 years of age living in one of the following Spanish provinces: Castellon, Valencia, Alicante, Murcia, Madrid, and Albacete.

\section{Methods}

SELECTION OF CASES

Records of all hospitals with existing services in paediatrics and haematology in the study area were examined to identify all cases of acute lymphoblastic leukaemia with histological diagnosis between January 1983 and June 1985 . Cases residing in that area at the time of diagnosis were included in the study. The total number of cases identified was 141 . Of these, 124 were alive at the time of the interview, and 17 were dead.

\section{SELECTION OF CONTROLS}

Controls were selected randomly from the census data. The last census had taken place in 1981 : annual updates of addresses were available, if they had been reported by the family to the census bureau. For each case, a list of potential controls was established based on the matching criteria of calendar year of birth, sex, and municipality at the time of diagnosis. The size of the municipalities ranged between 800 and three million subjects. The number of census tracts per municipality varied between one and more than 2000 . A census tract within a municipality (corresponding to a case's municipality) was randomly chosen to identify a control. A census tract included as many separate sheets of information on its residents as there were housing blocks. Sheets were ordered according to consecutive housing blocks. Within a census tract, a block was randomly selected, and a control of the same age and sex was sought. If a suitable control could not be found in the first block, the neighbouring block was assessed, and so on. All controls were selected within the same municipality as the case.

\section{DATA COLLECTION}

The data were collected in the months of March to July 1985 using personal interviews with the mothers of cases and of controls. Treating physicians contacted the cases to obtain informed consent. Controls were contacted directly by the interviewer. All the controls' mothers and $59^{\circ}{ }_{0}$ of the cases' mothers were interviewed at home while the others were interviewed at the hospital. The same interviewer was used throughout the study.

We report here only on occupational histories and exposures of mothers during pregnancy. Occupations were classified according to the Canadian Classification of Professions with a few minor changes to allow for the special characteristics of the studied population. An in depth interview of mothers elicited the reporting of a list of substances to which they were potentially exposed during each job performed while pregnant. An industrial hygienist helped with the identification of substances, and classified them into broad categories.

The following potential confounding factors were also measured: family history of cancer, use of medication (including hormones) by father and mother prior to pregnancy as well as during pregnancy for the mother, prenatal irradiation and infections, smoking, level of schooling for both parents, and family income.

\section{RESPONSE}

Among the 141 eligible cases, $128\left(91^{\circ}{ }_{0}\right)$ were interviewed. Thirteen of the eligible cases could not be interviewed: appointments could not be arranged for four cases, three could not be reached through the available addresses, three were on holidays, and three refused to participate.

Controls for 67 of the 128 cases were obtained from interviews with the first potential control selected from the census records. Two attempts were required for 31 controls, three for 10 , four for eight, five for six, and more than five for five. The 139 unsuccessful attempts were due to the potential control moving (59), no one being at home at the time that the interviewer called (44), and refusal to cooperate (36).

\section{ANALYSIS}

A conditional logistic regression model was used to analyse the one to one matched sets. BMDP2L was the program used for this analysis according to the suggestions of Hopkins and Hornung. ${ }^{22}$ Odds ratio and confidence intervals estimated with this method are equivalent to McNemar estimates in simple cases. Two sided significance levels ( $p$ values) against the null hypothesis of no association were obtained by referring the ratio of the log odds ratio to its standard error to tables of the standard normal distribution.

\section{Results}

The study included 70 boys and 58 girls. Among the cases, 13 had died. There were 65 subjects below four years of age, 37 between the ages of five and nine years, and 26 between 10 and 14 years. 
Table I shows the relative risks for leukaemia associated with mother's occupation during pregnancy. The relative risks were adjusted for birth year, sex, and place of residence (matching variables). The reference category always included all occupational categories other than the one for which the relative risk was estimated. Children of mothers working at home had a relative risk of $7.0\left(95^{\circ}{ }_{0} \mathrm{CI}=1.59-30.79\right.$, two sided $p=0.01$ ) of developing acute lymphoblastic leukaemia. A women was classified as working at home when she earned money for work performed in her home which was unrelated to her task of homemaker. The majority $(10 / 14)$ of women working at home were sewing fabric (cotton, wool, synthetic fibres) on a machine. The other women were involved in the production or repair of shoes.

When adjusted for household income and level of schooling of the mother, the relative risk of leukaemia associated with working at home was $5.78\left(95^{\circ}{ }_{0} \quad \mathrm{CI}=1 \cdot 27-26.25, \quad \mathrm{p}=0.02\right)$. The relative risk did not change appreciably when further adjusting for mother's use of prenatal exogeneous hormones, cancer in the family, smoking, viral infection, irradiation during pregnancy, and mother's age. Statistical interaction was studied for the category "working at home", with household income in three categories, presence of cancer in the family, and mother's smoking status during pregnancy. Interaction terms were not statistically significant at a $\mathrm{p}$ level of $0 \cdot 15$ or smaller.

Table II shows relative risks associated with selected exposures during pregnancy. Relative risks were adjusted for birth year, sex, and place of residence. Only exposure to organic dusts showed an increased risk more than could be accounted for by chance $\left(R R=5 \cdot 5 ; 95^{\circ}{ }_{0} C I=1 \cdot 21-24 \cdot 80\right.$, $\mathrm{p}=0.02$ )

To simplify computational problems resulting in non-convergence of matched analysis of

Table I Relative risks of acute lymphoblastic leukaemia in childhood according to mother's occupation during pregnancy

\begin{tabular}{lccccc}
\hline Occupation & Cases & Controls & $\begin{array}{c}\text { Discordant } \\
\text { pairs }\end{array}$ & $R R^{\mathrm{b}}$ & $95^{\circ}{ }_{0} C I^{\mathrm{c}}$ \\
\hline At home & 78 & 83 & $29 / 34$ & $0 \cdot 85$ & $0 \cdot 52-1 \cdot 40$ \\
Working at home & 14 & 2 & $14 / 2$ & $7 \cdot 00$ & $1 \cdot 59-30 \cdot 79$ \\
Professionals & 2 & 5 & $2 / 5$ & $0 \cdot 40$ & $0 \cdot 77-2 \cdot 06$ \\
Office work & 10 & 5 & $10 / 5$ & $2 \cdot 00$ & $0 \cdot 68-5 \cdot 85$ \\
Sales & 5 & 7 & $5 / 7$ & $0 \cdot 71$ & $0 \cdot 22-2 \cdot 25$ \\
Services & 5 & 11 & $5 / 11$ & $0 \cdot 45$ & $0 \cdot 15-1 \cdot 30$ \\
Agriculture & 9 & 5 & $9 / 5$ & $1 \cdot 80$ & $0 \cdot 60-6 \cdot 64$ \\
Industry & 5 & 10 & $5 / 10$ & $0 \cdot 50$ & $0 \cdot 17-1 \cdot 46$ \\
\hline
\end{tabular}

a Cases exposed-control unexposed/case unexposed-control exposed

$\mathrm{b}$ Relative risk

c $95^{\circ}$ ". Confidence interval

Table II Relative risks of acute lymphoblastic leukaemia in childhood according to mother's exposure during pregnancy

\begin{tabular}{|c|c|c|c|c|c|}
\hline Exposure & Cases & Controls & $\begin{array}{l}\text { Discordant } \\
\text { pairs }^{\mathrm{a}}\end{array}$ & $R R^{\mathrm{b}}$ & $95^{\circ}, C I^{\mathrm{C}}$ \\
\hline \multicolumn{6}{|l|}{ Dust: cotton, wool, } \\
\hline $\begin{array}{l}\text { synthet1c fibres } \\
\text { Solvents }\end{array}$ & $\begin{array}{r}12 \\
6\end{array}$ & $\begin{array}{l}3 \\
9\end{array}$ & $\begin{array}{r}11 / 2 \\
5 / 8\end{array}$ & $\begin{array}{l}5.50 \\
0.62\end{array}$ & $\begin{array}{l}1.21-24.80 \\
0 \cdot 20-1.91\end{array}$ \\
\hline Insecticides & 7 & 5 & $7 / 5$ & 1.40 & $0.44-4.41$ \\
\hline Oil, grease, hydrocarbons & 3 & 5 & $2 / 4$ & 0.50 & $0.09-2.73$ \\
\hline Biological products & 2 & 1 & $2 / 1$ & 2.00 & $0 \cdot 18-22 \cdot 05$ \\
\hline $\begin{array}{l}\text { Miscellaneous chemical } \\
\text { products }\end{array}$ & 3 & 3 & $3 / 3$ & - & - \\
\hline Electricity & 2 & 3 & $2 / 3$ & 0.66 & $0 \cdot 11-3.99$ \\
\hline
\end{tabular}

interaction between working at home and exposure to organic dusts, an unmatched analysis of interaction was conducted. This revealed a statistically significant interaction (likelihood ratio $\left.\chi^{2}, 1 \mathrm{df}=5.4, \mathrm{p}=0.02\right)$. Among women working outside the home, those exposed to organic dusts had no increased risk (two cases and three controls, odds ratio $=0.73,95^{\circ}$. $\mathrm{CI}=0.08$ $5 \cdot 50)$. Risk in women working at home unexposed to organic dusts was increased compared to other unexposed women, but not significantly so (four cases and two controls, odds ratio $=2 \cdot 34,95^{\circ}$, $\mathrm{CI}=0.34-17.03)$. Thus most of the elevated risk in women working at home was due to organic dusts. The odds ratio for these women relative to unexposed women working outside the home was infinite (10 cases and no controls, exact lower $\mathrm{CI}=2 \cdot 34)$

\section{Discussion}

None of the previous studies on the relationship between mother's occupation and the incidence of leukaemia among children had suggested that working at home was a risk factor. In this study, working at home implied machine sewing of clothing or some step in the production of shoes and in most instances the women were hired by industries to do the work. The results suggested that the risk may have been confined to women exposed to organic dusts (those who sewed).

The selection of controls could be a source of bias. We are confident, given the geography of the region and our knowledge of the health facilities in this area, that the ascertainment of cases for this study would have missed very few if any cases residing in the study area. In this situation, the best control group is a sample of the same population without the disease. ${ }^{23}$ Previously used sources for population controls in similar studies, such as birth certificates, or random digit dialling were not feasible. Birth certificate information is not centralized in Spain: it is found in municipal registries where the child was born, and is generally not computerized. Moreover, the probability of picking controls who no longer live at the birth address seems likely to be high. As for random digit dialling, its use is not recommended in Spain since only $54.4^{\circ}{ }_{0}$ of households have a telephone. ${ }^{24}$

Children living in the same municipality as the case at the time of diagnosis were considered a reasonable choice for the study base. However, only families (children) who resided in the addresses registered in the census office were sampled as controls, whereas cases could still be included in the study if they had moved after the diagnosis, or between census enumeration and diagnosis, even if they had failed to register the change of address. Twenty two per cent of sampled control addresses (59/267) were no longer valid. If the fact that the mother worked at home was importantly associated with mobility and with conscientiousness in registering change of address, then the proportion of control mothers working at home in the base population is underestimated in this study. This would lead to an inflated relative risk estimate of acute lymphoblastic leukaemia in association with the factor "mother working at home". 
Is it likely that a mother working at home was a frequent determinant of not being at the address registered in the census office? No direct evidence can be provided to answer this question. However, a "worst case" sensitivity analysis was done assuming that unlocated controls $(22 \%)$ were 10 times more likely to be working at home than the successfully interviewed controls $(78 \%)$. Results showed a reduced risk, which was nevertheless still increased $(R R=2 \cdot 8)$ and statistically significant (two sided $\mathrm{p}$ value $<0.05$ ).

Because of limited resources, all control families were visited without notice, at varying hours during the day or the night, and the interviewer travelled only briefly in each province to locate them. The reasons for not locating controls were most likely varied, thus probably not resulting in any strong bias. Likewise, a large bias associated with refusals seems unlikely. Lack of interest was the main reason. In small villages, refusals were not as common as in capitals, suggesting that awareness of the cancer case in another family increased interest in the survey.

A further bias could have resulted from the interviewer not being blind to the disease status. However, a biased interviewer would tend to elicit known risk factors as opposed to unsuspected ones such as working at home. No particular emphasis was put on them since working at home was not envisaged as a risk factor from previous studies. Classification of interview responses of mothers according to occupation and to exposure was done blindly also reducing the possibility of bias.

Recall bias was also possible although it is not obvious how this could have affected the ascertainment of an occupation category such as working at home. Moreover, the assessment of factors such as self medication during pregnancy, cancer in the family, and exposures to potentially toxic material at home during pregnancy did not appear overestimated in cases as compared to controls. Errors in the classification of cases would also seem unlikely since the diagnosis of acute lymphoblastic leukaemia according to histological material is generally not subject to controversy. Errors in the classification of exposures are possible and may have affected cases as well as controls in a non-differential manner, causing a bias in odds ratio towards the null.

Finally, although the lower confidence limit for the odds ratio for working at home (1.59) was not very far from unity, the chance that this increased risk was a random occurrence (the significance level) was low, at $p=0 \cdot 01$. However, given this is a hypothesis generated from investigating several associations, this nominally small $p$ value should not be interpreted at totally excluding chance as a cause.

Among the previous studies on parental occupation and cancer in children, only a few used face to face interviews to assess occupations and exposures. Most used job descriptions available from birth certificates or other methods such as postal or telephone questionnaires. Other studies have not shown the category "working at home" in the list of mothers' occupations. Perhaps mothers were not asked if they worked at home or this type of work was very unusual in the areas in which the studies were conducted.
It is not clear which aspects of sewing at home are to be incriminated, if any. Women were exposed to organic dust and synthetic fibres, but also to oil and grease from the machines with which they worked. Moreover, the environment in which such exposures occurred most probably differed in many ways from the industrial environment in which they are usually encountered. We have found no other data strictly comparable to ours in the literature. However, Van Steensel-Moll and Valkenburg ${ }^{17}$ have previously suggested that the risk for a child developing leukaemia when the mother was working in the textile industry during pregnancy was $4 \cdot 2(95 \% \mathrm{CI}=1 \cdot 0-17 \cdot 7)$. Siemiatycki et al ${ }^{25}$ observed among adult workers an odds ratio of 1.9 $(1 \cdot 0-3 \cdot 7)$ for non-Hodgkin lymphomas in association with exposure to cotton dust. The odds ratio reached $12.6(4 \cdot 7-33 \cdot 3)$ when only workers with a strong exposure were considered. In a review of 12 studies on cancer as an occupational disease, Dubrow and Wegman ${ }^{26}$ showed that textile workers had a slightly elevated risk for mouth cancer. In the same year, a mortality study of 4500 women in the textile industry suggested a modestly elevated risk for certain types of cancer such as non-Hodgkin lymphomas and leukaemia. ${ }^{27}$ Moreover, work with textiles has been associated with excesses of several other cancer sites. ${ }^{25} 28-30$

There have not been many hypotheses proposed on the carcinogenic mechanisms of tissue dust. Siemiatycki et $a l^{25}$ speculated that dyes used for synthetic fibres could be responsible for the previously shown deleterious effects, that synthetic fibres could permit greater leaching of dyes once the fibres are ingested in the organism, and that synthetic fibres themselves could be metabolised into carcinogenic agents. However, no hypothesis has been put forward to explain the association between exposure to cotton dust and cancer. On the contrary, Enterline et al ${ }^{31}$ have suggested that endotoxins in cotton dust are potent anticancer agents, and this may explain the lower death rates from cancer observed among cotton textile workers. Of course, the fetus, exposed through the placental circulation, may react differently from the adult worker.

In this study, office workers and agricultural workers had relative risks which were raised, but not significantly so. The latter were mostly exposed to insecticides, fertilisers, and pesticides. The relativate risk for exposure to such substances was $1.4 \quad(95 \% \quad \mathrm{CI}=0 \cdot 44-4 \cdot 41)$. Different types of cancer have been shown to be associated with exposure to such substances. ${ }^{32} 33$ Moreover, three studies similar to ours have found an association between parental exposure to pesticides and the development of leukaemia in children. ${ }^{151619}$ The only explanation that can be offered for the increased relative risk of leuakaemia observed among children of office workers is that this disease has been reported more frequently among higher socioeconomic classes. ${ }^{34}$

An unknown confounding variable which would select women to work at home and at the same time be a cause for cancer in children cannot be excluded. However, none of the variables measured (including maternal diseases) was 
shown to be a confounder in our data. The possibility that after birth there is continued exposure of the child to carcinogens in the home through mother's work cannot be excluded in this study.

In conclusion, this study is the first to suggest an association between mother working (sewing of various kinds) at home during pregnancy, and acute lymphoblastic leukaemia in children. Further studies are needed to confirm this finding. Previous ones could also be reanalysed in this perspective; it is likely that several women in previous similar studies worked at home, many probably sewing. Very little is known about the working conditions of men and women in these circumstances. The level of contamination in the atmosphere may be higher given a ventilation that is probably inadequate. Moreover, the fabrics that are worked on may be more toxic. Among Spanish control mothers, $1.5 \%(2 / 128)$ were working at home. If this figure is close to the current extent of working at home among women in similar countries, we might have a new occupational health concern on our hands.

Dr $\mathbf{R}$ Peris from the Children's National Tumor Registry (RNTI) helped in the ascertainment of cases, Dr A Silvestre helped contact parents, Mr A Nolasco helped with data coding and preliminary statistical analysis, Dr J Siemiatycki provided advice on the treatment of information and on ways to interpret it, $\mathrm{Mr}$ $J$ Deadman suggested the exposure classification, and Dr R Rothenberg provided helpful comments on an earlier draft. This work would not have been possible without the cooperation of the following clinicians: Drs V Castell, T Hurtado, J Lopez, R Calatayud, T Contra, C Valverde, A Morales, M Bernacer, A Muñoz, C Estellés, M L Marti, R Trenor, V Alvarez, E Buesa, J Donat, A M Lastra, J M Fernandez-Rañada, J GarciaConde, and P Zabala.

1 Neglia JP, Robison LL. Epidemiology of the childhood acute leukaemia. Pediatr Clin N Am 1988; 35: 675-92.

2 Aldrich TE, Easterly CE. Electromagnetic fields and public health. Environ Health Perspect 1987; 75: 159-71.

3 Savitz DA. Childhood cancer. Occup Med (State of the Art Reviews) 1986; 1: 415-29.

4 Arundel SE, Kinnier-Wilson LM. Parental occupations and cancer: a review of the literature. $\mathcal{f}$ Epidemiol Community Health 1986; 40: 30-6.

5 Fabia J, Thuy TD. Occupation of father at time of birth of children dying of malignant diseases. Br f Prev Soc Med 1974; 28: 98-100.

6 Hakulinen T, Salonen T, Teppo L. Cancer in the offspring of fathers in hydrocarbon-related occupations. Br $\mathcal{F}$ Prev of fathers in hydrocarbon-r
Soc Med 1976; 30: 138-40.

7 Kwa SL, Fine LJ. The association between parental occupation and childhood malignancy. $\mathcal{F}$ Occup Med 1980;
22: 792-94.
8 Zack M, Cannon S, Loyd D, et al. Cancer in children of parents exposed to hydrocarbon-related industries and occupations. Am f Epidemiol 1980; 111: 329-36.

9 Hicks N, Zack M, Caldwell GG, Fernbach DJ, Falletta JM Childhood cancer and occupational radiation exposure in parents. Cancer 1984; 53: 1637-43.

10 Hemminki K, Saloniemi I, Salonen T, Partanen T, Vainio $H$. Childhood cancer and parental occupation in Finland. $f$ Epidemiol Community Health 1981; 35: 11-15.

11 Sanders BM, White GC, Draper GJ. Occupations of fathers of children dying from neoplasms. $\mathcal{F}$ Epidemiol Community Health 1981; 35: 245-50.

12 Gold EB, Diener MD, Szklo M. Parental occupation and cancer in children. $\mathcal{F}$ Occup Med 1982; 24: 578-84.

13 Shaw G, Lavey R, Jackson R, Austin D. Association of childhood leukemia with maternal age, birth order, and childhood leukemia with maternal age, birth order, and

14 Vianna NJ, Kovasznay B, Polan A, Ju C. Infant leukemia and paternal exposure to motor vehicle exhaust fumes. $\mathcal{F}$ Occup Med 1984; 26: 679-82.

15 Lowengart RA, Peters JM, Ciconi C, et al. Childhood leukemia and parents' occupational and home exposures. $f$ Natl Cancer Inst 1987; 79: 39-46.

16 Buckley JD, Robinson LL, Arthur D, et al. Occupational exposures of parents of children with acute nonlymphocytic leukemia (abstract). Am $\mathcal{F}$ Epidemiol 1987; 126: 767-8.

17 Van Steensel-Moll HA, Valkenburg HA, Van Zanen GE. Childhood leukemia and parental occupation. $A m \dot{f}$ Epidemiol 1985; 121: 216-24.

18 McKinney PA, Cartwright RA, Saiu JMT, et al. The inter-regional epidemiological study of childhood cancer IRESCC): a case control study of aetiogical factors in leukaemia and lymphoma. Arch Dis Child 1987; 62: 279-87.

19 Shu XO, Gao YT, Brinton LA, et al. A population-based case-control study of childhood leukemia in Shanghai. Cancer 1988; 62: 635-44.

20 Feingold L, Savitz D. Risk of childhood cancer in relation to parental occupation (abstract). Am $\mathcal{F}$ Epidemiol 1988; 128 . 912 .

21 Laval G, Tuyns AJ. Environmental factors in childhood leukaemia. $\mathrm{Br} \mathcal{F}$ Ind Med 1988; 45: 843-4.

22 Hopkins A, Hornung R. New $2 L$ features with illustrative examples. Technical Report No 80. Los Angeles: BMDP examples. Technical Report
Statistical Software. 1985.

23 Kelsey JL, Thompson WD, Evans AS. Methods in observational epidemiology. New York: Oxford University

24 Telefónica a 15 años del año 2000. Ed por Servicio Publico de Telefónica, 1985

25 Siemiatycki J, Richardson L, Gerin M, et al. Associations between several sites of cancer and nine organic dusts: results from an hypothesis generating case-control study in Montreal, 1979-1983. Am f Epidemiol 1986; 123: 235-49.

26 Dubrow R, Wegman DH. Setting priorities for occupational cancer research and control: synthesis of results of occupational disease surveillance studies. $\mathcal{f}$ Natl Cancer Inst 1983; 71: 1123-42.

27 Dezell E, Grufferman S. Cancer and other causes of deaths among female textile workers, 1976-78. I Natl Cancer Inst 1983; 71: 743-40.

28 Vobecky J, Devroede G, Caro J. Risk of large bowel cancer in synthetic fiber manufacture. Cancer 1984; 54: 2537-42.

29 Dubrow R, Gute DM. Cause-specific mortality among male textile workers in Rhode Island. Am F Ind Med 1988; 13: 439-54.

30 Brinton LA, Blot WJ, Fraumeni JF. Nasal cancer in the textile and clothing industries. Br $\mathcal{F}$ Ind Med 1985; 42 : 469-74.

31 Enterline PE, Sikora JL, Keleti G, Lange JH. Endotoxins, cotton dust, and cancer. Lancet 1985; ii: 934-35.

32 Sterling TD, Arundle AV. Health effect of phenoxyherbicides: a review. Scand $\mathcal{F}$ Work Environ Health 1986; 12: 161-73

33 Editorials. Herbicide exposure and cancer. $\mathcal{F} A M A$ 1986; 256: 1176-8

$34 \mathrm{McWhirter}$ WR. The relationship of incidence of childhood lymphoblastic leukaemia to social class. $\mathrm{Br} \mathcal{F}$ Cancer 1982 46: $640-5$. 